\title{
O Perfil De Gravidade Dos Pacientes De Centro De Terapia Intensiva Em Hospital Universitário Do Rio Grande Do Sul
}

\author{
Knijnik, L.M.; Fernandes, V.F.; Sganzerla, G.Z.; \\ Apresentador: Leonardo Mees Knijnik
}

\section{Resumo}

Introdução: Os Centros de Terapia Intensiva (CTI) são unidades de internação com características distintas das enfermarias restantes. Vários indicadores revelam indiretamente o perfil de pacientes e intervenções de um CTI, e entendê-los pode melhorar a qualidade assistencial e aprofundar o conhecimento sobre as causas de morbimortalidade dessa Unidade. Este trabalho teve como objetivo avaliar a taxa de retorno ao CTI e parâmetros de gravidade para caracterizar o perfil de pacientes que são atendidos na CTI do Hospital de Clínicas de Porto Alegre (HCPA). Métodos: Dados epidemiológicos retrospectivos do CTI adulto foram retirados da base de dados hospitalares do HCPA, IG-BSC, entre jan/2002 em maio/2014, incluindo taxa de retorno, média de permanência, CID da internação e escore APACHE de gravidade. Após, as médias e taxas foram calculadas através do software Excel 2013. Resultados: A taxa de retorno ao CTI foi de 764 pacientes sobre 20.549 $(3,72 \%)$. A média de permanência foi de 5,49 dias. Utilizando somente os cadastros válidos do escore de gravidade APACHE, 5.363 de 10.627 pacientes $(50,5 \%)$ tinham score maior ou igual a 20 , correspondendo a prognóstico de mortalidade maior ou igual a 40\%. O diagnóstico da internação (CID) mais frequente foi "Doenças do Aparelho Circulatório", correspondendo a 9.318 de 22,410 (41,6\%) dos casos. Conclusão: O perfil dos pacientes que internam na CTI do HCPA é, de acordo com prognóstico dado pela escala APACHE, extremamente grave, e tem tempo médio de internação baixo, possivelmente devido a alta mortalidade desses pacientes. A taxa de retorno, marcador de mal prognóstico, no entanto, é menor em relação ao descrito na literatura brasileira e internacional. Estudos de coorte são necessários para estabelecer as relações entre taxa de retorno e mortalidade no HCPA.

\section{Referência:}

Knijnik, L.M.; Fernandes, V.F.; Sganzerla, G.Z.; O Perfil De Gravidade Dos Pacientes De Centro De Terapia Intensiva Em Hospital Universitário Do Rio Grande Do Sul. In: II Congresso Brasileiro de Medicina Hospitalar - II CBMH [= Blucher Medical Proceedings, vol.1, num.5] São Paulo: Editora Blucher, 2014. p.30

DOI 10.5151/medpro-II-cbmh-023 